\title{
Land Use / Land Cover Assessment in Nagercoil town, Kanniyakumari District, South India
}

\author{
Shafiullah. G \\ Department of Earth and Environmental Sciences, Kuwait University, Kuwait
}

\begin{abstract}
The present study revealed land use / land cover (LULC) changes during 1992 to 2015 using remote sensing and GIS tools. NRSC land use / land cover thematic maps were referred for classifying the LULC classification. For this assessment, ERDAS image software using maximum likelihood tool in supervised classification is applied. The present study identified land use / land cover pattern of the Nagercoil town is composed of build up land, agriculture land, plantation, crop land and water bodies. Therefore, the land use land cover changes were assessed from 1992 to 2015 and the results show that build up land has increased $8 \mathrm{~km} 2$, agriculture land has decreased $3.64 \mathrm{~km}^{2}$, plantation has decreased $2 \mathrm{~km}^{2}$, crop land has decreased $2 \mathrm{~km}^{2}$ and water bodies have decreased $0.36 \mathrm{~km}^{2}$.
\end{abstract}

Keywords- Land Use/Land Cover, classification, change detection.

\section{INTRODUCTION}

The recent and high-resolution remote sensing data are very useful for future and planning studies like land use / land cover, geomorphology, NDVI, NDWI and etc. Land use / land cover study has very important applications for current strategies for managing natural resources and monitoring the environmental changes, and it is an active process of finding habitation on the physical surfaces (Ravatet al. 2013). Land use / land cover arrangement and alteration are significant factors that affect ecosystem condition and function (Lunetta et al. 2006). The LULC study assists the decision makers and researchers to plan sustainable development and to understand the changes of environment Iqbal and Khan. 2014). Remote sensing studies are a critical and worldwide tool for land use land cover management and monitoring in many agencies which is being used mostly in change detection analysis (Kennedy et al. 2009). Landsat data has constituted the longest record of large scale medium spatial resolution earth observation data (Hansen and Loveland 2012). The main aim of the study is to assess the changes of LULC of Nagercoiltown in Kanniyakumari district, South India. The main objectivesare to delineate the land use/ land cover map and to assess the changes from land use / land cover map.

\section{MATERIAL AND METHOD}

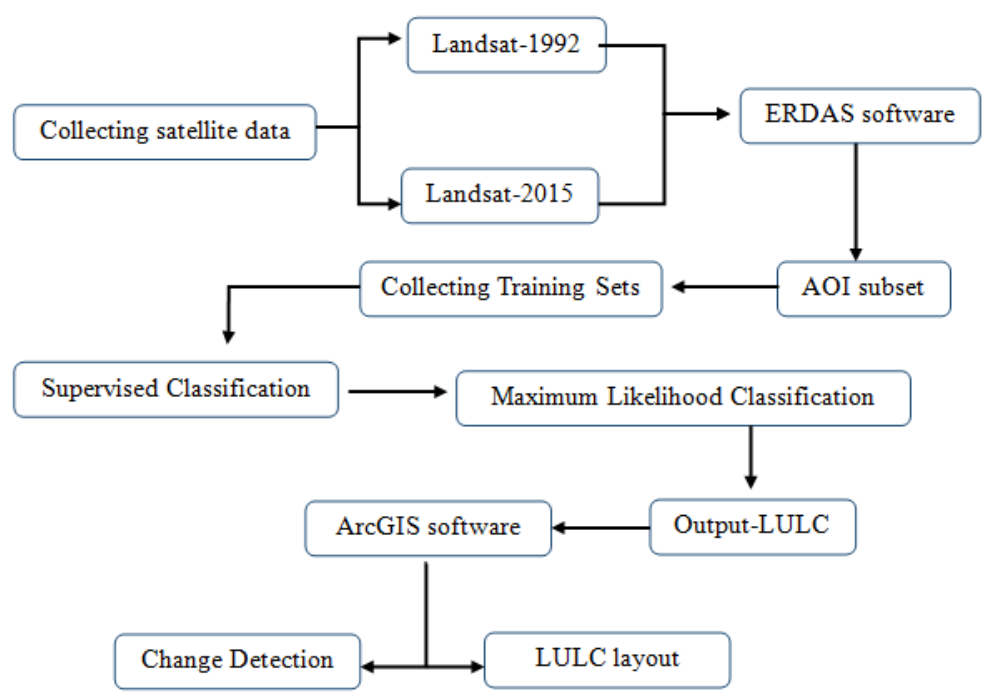

Fig.1: A detailed flow chart methodology of the present study 
Survey of India Toposheets, 1:50,000 scale, (1972-74)

Landsat imagery (1992-2015)

ERDAS-Image processing software

ArcGIS software

The above flowchart methodology are adopted for the present study (Fig.1)

\section{STUDY AREA}

The chosen study area is Nagercoil town in Kanniyakumari district, South India (Fig.2). The Nagercoil town geographically lies between $8^{\circ} 9$ ' 0 " to $8^{\circ} 13$ ' 0 " north latitudes and $77^{\circ} 23^{\prime} 30^{\prime \prime}$ to $77^{\circ} 27^{\prime}$ " ${ }^{\prime}$ east longitudes; which is almost covered by $36 \mathrm{~km}^{2}$. It is located on the southernmost tip of India and is surrounded by Tirunelveli on its east and north and by Kerala on its west and northwest.As per the 2011 census, the total population in this town is 224,849 and the density of this town 9813 people per $\mathrm{km}^{2}$. The town is surrounded by hills and lush green fields. The average elevation of the study area is approximately $40 \mathrm{~m}$. During the summer season the temperature reaches at $34^{\circ} \mathrm{C}$ which is from March to end of May. During the monsoon season the average temperature is about $25^{\circ} \mathrm{C}$. The winter season starts from November to end of February with an average temperature $22^{\circ}$ C.Nagercoil is one of the main hubs of the industrial and commercial activity in the kanniyakumari district.

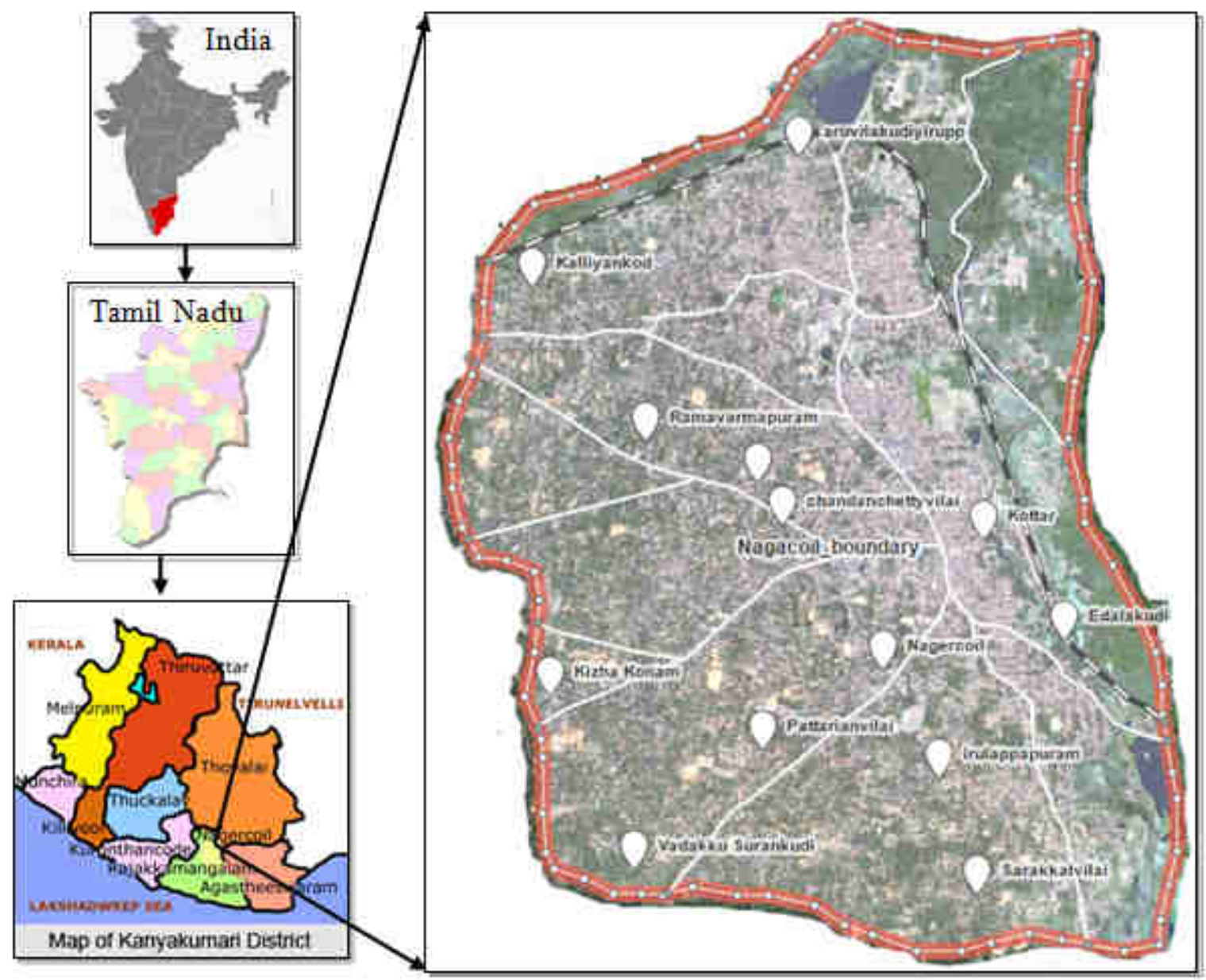

Fig.2: Key map of the study Area

\section{RESULTS AND DISCUSSION}

The present study carried out the land use / land cover assessment analysis using satellite data during 1992 to 2015. The NRSC land use / land cover thematic maps were referred for study area classification. Generally the study www.ijeab.com area covered by built up land, agriculture land, plantation land, cropland and water bodies. The land use / land cover classification has been done on the basis of the level one classification based NRSC LULC classification table and the results are given in table 1 .

Page | 1042 
Table.1: Results of LULC classificationand Changes between 1992 and 2015

\begin{tabular}{|c|c|c|c|c|c|c|c|}
\hline \multirow{2}{*}{$\begin{array}{l}\text { S. } \\
\text { No. }\end{array}$} & \multirow{2}{*}{ Classes } & \multicolumn{2}{|c|}{1992 LULC Classified image } & \multicolumn{2}{|c|}{2015 LULC Classified image } & \multicolumn{2}{|c|}{$\begin{array}{c}\text { Changes between } \\
\text { 2015- } 1992\end{array}$} \\
\hline & & Area $\mathrm{km}^{2}$ & Percent age & Area $\mathrm{km}^{2}$ & Percent age & $\begin{array}{l}\text { Area } \\
\mathrm{km}^{2}\end{array}$ & $\begin{array}{l}\text { Percent } \\
\text { age }\end{array}$ \\
\hline 1 & Build up land & 7 & 19.20 & 15 & 40.9 & +8.0 & +21.7 \\
\hline 2 & Agriculture land & 16.64 & 45.20 & 13 & 35.6 & -3.64 & -9.6 \\
\hline 3 & Plantation & 7 & 19.20 & 5 & 13.6 & -2.0 & -5.6 \\
\hline 4 & Crop land & 5 & 13.70 & 3 & 8.2 & -2.0 & -5.5 \\
\hline 5 & Water bodies & 1 & 2.70 & 0.64 & 1.7 & -0.64 & -1.00 \\
\hline
\end{tabular}

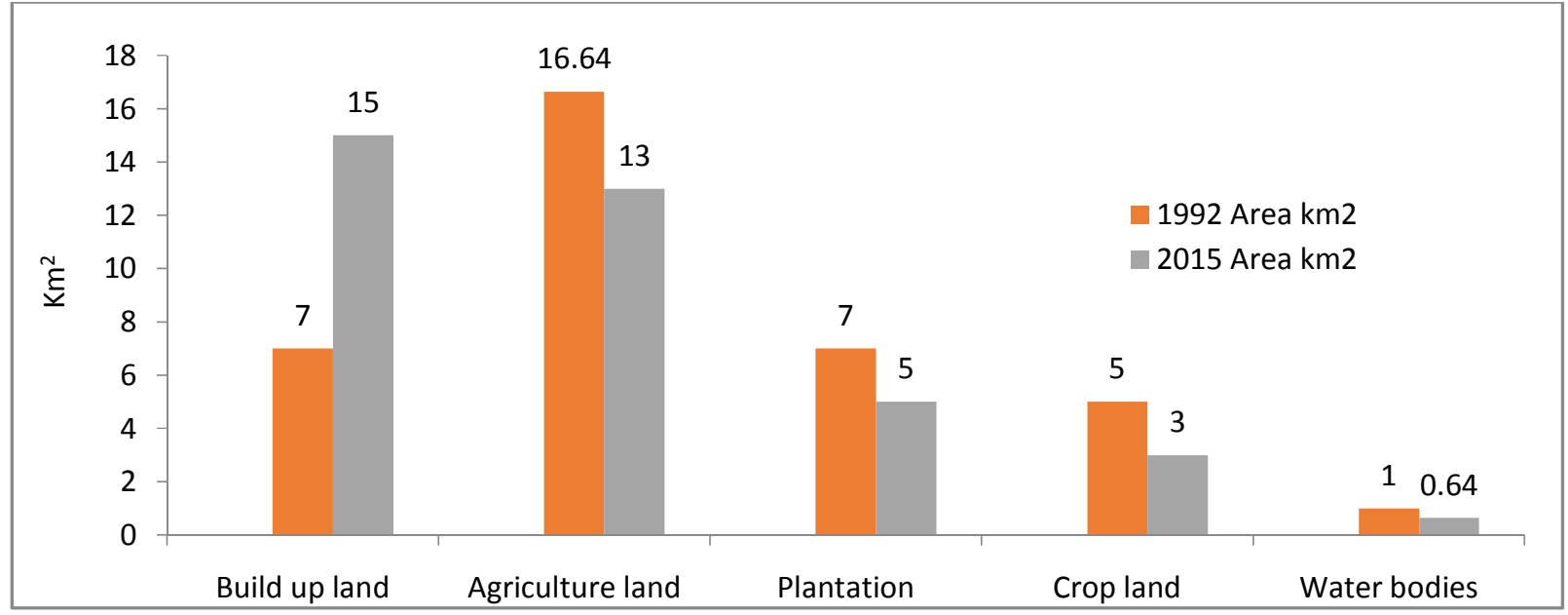

Fig.3: Change Detection of land pattern between 1992 and 2015

Graph (Fig. 3) shows the difference between the two years classification changes in $\mathrm{Km}^{2}$. During the year 1992 land use/ land cover results representing the build up land, agriculture land, plantation, crop land and water bodies covered an area of $7 \mathrm{~km}^{2}$, $16.64 \mathrm{~km}^{2}, 7 \mathrm{~km}^{2}, 5 \mathrm{~km}^{2}$ and $1 \mathrm{~km}^{2}$, respectively. The spatial distribution map of the 1992 LULC map is given in Fig. 4. 


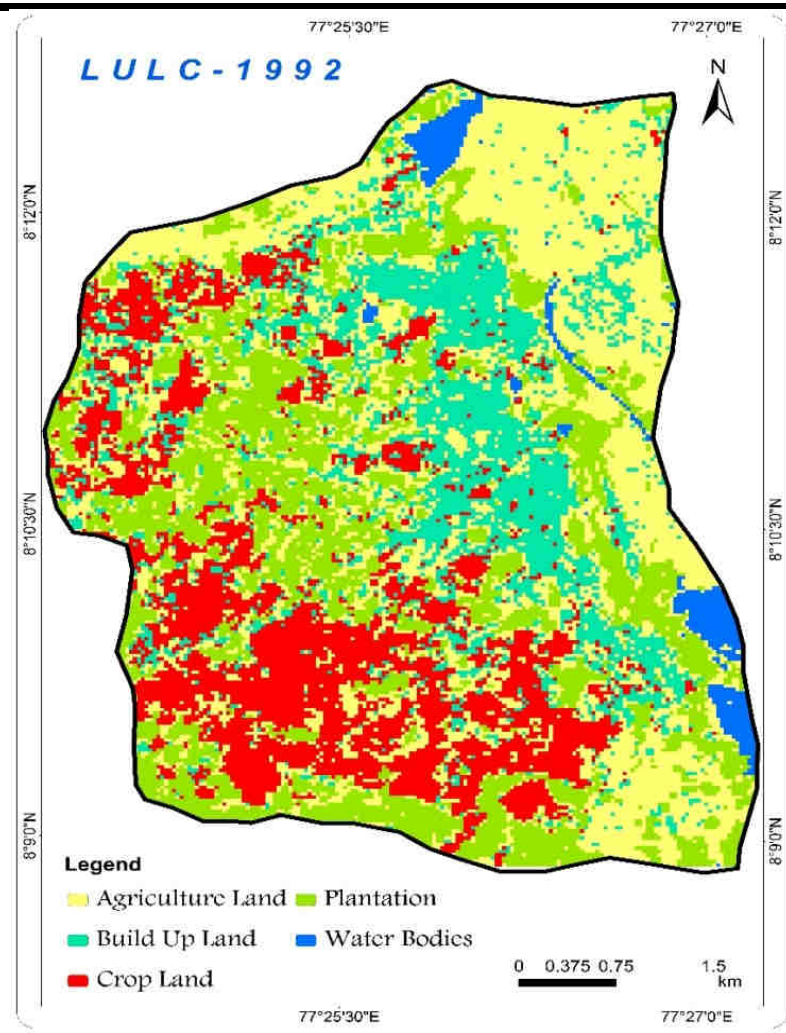

Fig.4: Spatial distribution of LULC pattern (1992)

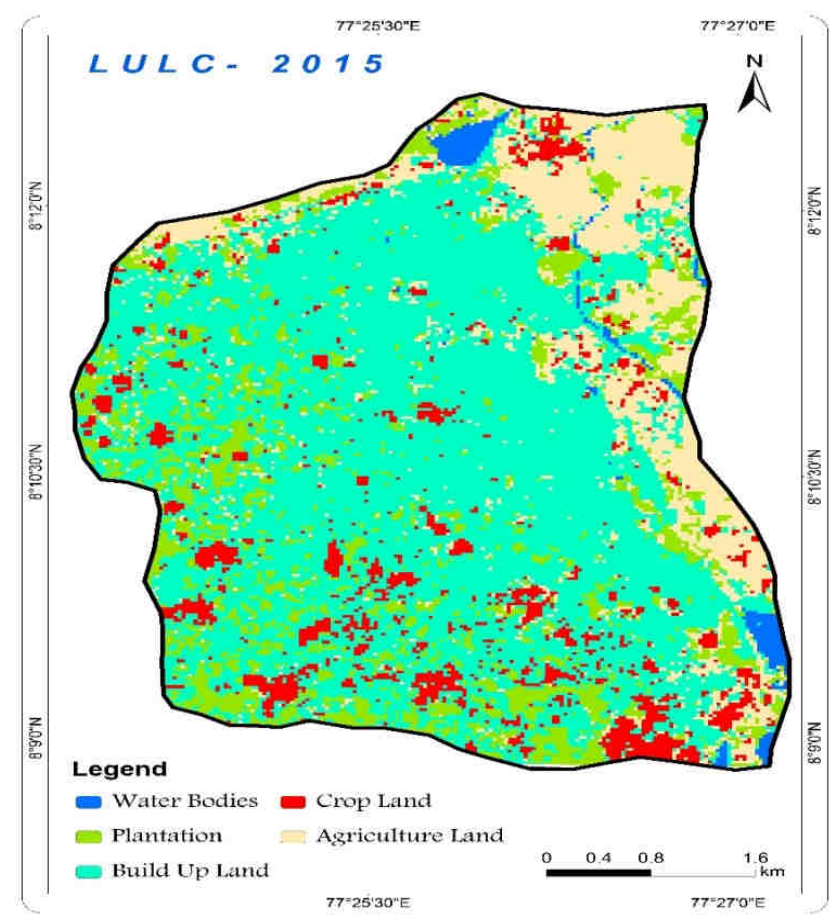

Fig.5: Spatial distribution of LULC pattern (2015)

In the year 2015, the land use / land cover pattern in study area was totally changed into build up land $15 \mathrm{~km}^{2}$, agriculture land $13 \mathrm{~km}^{2}$, plantation $5 \mathrm{~km}^{2}$, crop land $3 \mathrm{~km}^{2}$ and water bodies $0.64 \mathrm{~km}^{2}$ only. The spatial distribution map of the 2015 LULC map is given in Fig. 5. Obviously 
the results are showing the maximum changes in the land use / land cover pattern of the study area.

\section{CONCLUSION}

The land use/ land cover study as made from Nagercoil town, Kanniyakumari district, South India. During the study period from 1992 to 2015 for overall 23 years difference, the study area has been totally changed. The changes are water bodies were decreased to $0.36 \mathrm{~km}^{2}$, agriculture lands decreased to $3.64 \mathrm{~km}^{2}$, built up lands increased 8 $\mathrm{km}^{2}$,plantation lands decreased $2 \mathrm{~km}^{2}$ and crop lands were also decreased $2 \mathrm{~km}^{2}$. During these 23 years interval, due to the urban growth, the built - up lands increased $21.7 \%$, while the agriculture, plantation, crop land and water bodies were decreased the same $(21.7 \%)$ percentages. So, all other four types of lands that are agriculture, plantation, crop land and water bodies decreased $21.7 \%$ into develop only the build up land in this area.

\section{REFERENCES}

[1] Lunetta, R. S., Knight, J. F., Ediriwickrema, J., Lyon, J. G. \&Worthy, L. D. Land cover change detection using multi temporal MODIS NDVI data. Remote sensing of Environment, 105:142-154.

[2] Rawat, J. S., Biswas, V. \& Kumar, M. Changes in land use /cover using geospatial techniques: A case study of Ramnagar town area, district Nainital, Uttarakhand, India. Egypt. J. Remote Sens. Sp. Sci. 16, 111-117 (2013).

[3] Muhammad Farooq Iqbal and Iftikahar Ahmad Khan. (2014). "Spatiotemporal Land Use Land Cover change analysis and erosion risk mapping of Azad Jammu and Kashmir, Pakistan". The Egyptian Journal of Remote Sensing and Space Sciences.17:209-229.

[4] Matthew C. Hansen and Thomas R. Loveland (2012). "A review of large area monitoring of land cover change using Landsat data". Remote sensing of Environment. 122: 66-74.

[5] Robert E. Kennedy, Townsend, P.A. and Gross, J.E. (2009). "Remote sensing change detection tools for natural resource managers: Understanding concepts and tradeoffs in the design of landscape monitoring projects". Remote sensing of Environment 113:13821396 